[DOI: 10.24214/jecet.A.9.1.13848.]

Journal of Enviranmental Science, Computer Science and Engineering \& Technology

An International Peer Review E-3 Journal of Sciences and Technology

Available online at www.jecet.org

Section A: Environmental Science

Research Article

\title{
Re-refining of used lubricating oil using a mixture of N-Methyl-2-Pyrrolidone and Butanol
}

\author{
M. Hussein'1, A. A. Amer'1, A. S. Gabrah², M.Attia ${ }^{1}$ \\ ${ }^{1}$ Department of chemical engineering, Alexandria University, Alexandria, Egypt \\ ${ }^{2} \mathrm{PhD}$ in used lube oils re-refining, Department of chemical engineering, Alexandria \\ University, Alexandria, Egypt
}

Received: 21 December 2019; Revised: 06 January 2020; Accepted: 15 January 2020

\begin{abstract}
This study aims to investigate a process of solvent extraction of used lubricating oils using solvent extraction process. Experiments were carried out on pretreated used oils from Alexandria petroleum company (A.P.C) where most of the light hydrocarbons and water were removed. Used oils were subjected to solvent extraction of base oil using mixture of solvents consists of N-methyl-2-pyrrolidone (NMP) and butyl alcohol .Bench scale study was carried out to investigate of different variables including solvent to solvent ratio, solvent to oil ratio, mixing time, mixing speed, and temperature. Factorial design method which is generated by MINITAB (version 17) statistical analysis software was used to study the factors affecting on the percentage sludge removal (PSR) from used lube oils, Where the highest PSR obtained was 55.3\% at (solvent to solvent ratio \%wt.0.75, solvent to oil ratio 6, extraction temperature $60^{\circ} \mathrm{C}$, mixing time $50 \mathrm{~min}$. and mixing speed at $600 \mathrm{RPM}$ ) while the lowest was $18.86 \%$ at (solvent to solvent ratio \%wt.0.25, solvent to oil ratio 2, extraction temperature $25^{\circ} \mathrm{C}$, mixing time $10 \mathrm{~min}$. and mixing speed at $600 \mathrm{RPM}$ ) .
\end{abstract}

Keywords: Lubricating oil, solvent extraction, T-value, hydrocarbons 


\section{INTRODUCTION}

Lubricating oil is one of the vital liquids that are used in majority of all vehicles and machines. Lubricating oils play a dual role of heat transfer and that of friction reduction that reduces the heat generated in internal combustion engines [1]. Lubricating oil becomes misfit for further use for the following reasons: accumulation of contaminants in the oil and chemical changes in the oil. In addition, there is a shortage of prime lubricating oils that is hard to make up and needs use of hard-to-replace petroleum for products other than fuels. Resource preservation and issues related to the oil disposal are priorities that order the expansion of the re-refining option ${ }^{[2]}$. Processes for recovery of used oil vary from simple settling or filtration to solvent extraction or vacuum distillation or a combination of these and other processes ${ }^{[3]}$. Among the alternative processes practiced for recycling used lubricating oils during recent years, solvent extraction process has received considerable attention [4]. The solvent extraction replaces the classic and common acid-clay treatment successfully. In this process solvent has to mix with waste lubricant oil in proper ratio and fully miscible with the base oil and reject impurities (carbonaceous and additives) generally found in waste oils that flocculates and settled down due to gravity action, then recover the used solvent for recycle purpose during distillation [5]. The advantages of NMP over other commonly used solvents are: the non-toxic nature and high solvent power, the ease of recovery from solutes and its high selectivity for aromatic hydrocarbons ${ }^{[6]}$. The alcoholic solvents such as butyl alcohol have a hydroxyl group $(\mathrm{OH}-)$, which provides an electrostatic media that encourage fine particles to agglomerate into large flakes. Higher solubility in the base oil refers to higher miscibility of the solvent in base oil which decreases the amount of oil losses in the sludge ${ }^{[7]}$.

Fractional factorial design are experimental designs consisting of a carefully subset of the experimental runs of a full factorial design. In addition, it explores the effect of different combinations of factor values on process outputs that are carried out on a subset of all possible values rather than the complete set of possible values. Fractional factorial designs are used when only some possible values of factors in a process are seen as relevant to the business or manufacturing process being modeled in addition to the fractional factorial design are a good choice when resources are limited or the number of factors in the design is large ${ }^{[8-11]}$

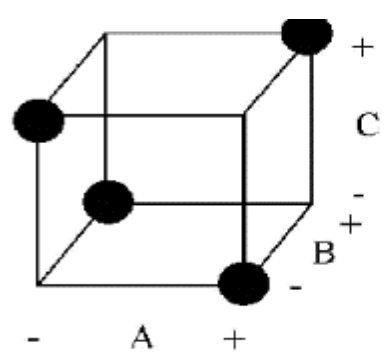

\section{EXPERIMENTAL}

Used oils: In this study, the samples were collected from the output of unit 10 in used oil re-refining department at Alexandria Petroleum Company (A.P.C) which uses a KTI re-refining technology. The input of unit 10 is used lubricating oil collected and gathered from different service stations were it is allowed to homogenize and settle in tanks so that the free water and any settable suspended solids could be removed.

In unit 10 many impurities, water and gas oil were removed from used oil, where the feed pass through a series of filters to remove and strip solids and impurities. Then the used oil neutralized by the addition of $10 \% \mathrm{NaOH}$ in a neutralization vessel or container. Water was removed in a water removal vessel at $160{ }^{\circ} \mathrm{C}$ and the temperature of the used oil was raised to $260{ }^{\circ} \mathrm{C}$ under vacuum pressure in a distillation 
column to remove raw gas oil. Which in turns to lead to give us lubricating oil which has been used in this study and can be considered as a pre-treated oil after removal of impurities, gas oil and water. ${ }^{[10]}$

\section{Solvents used}

(i).N-Methyl-2-pyrrolidone (NMP)

(ii).Butyl alcohol

\begin{tabular}{|l|l|l|}
\hline Physical property & Butyl alcohol & NMP \\
\hline Chemical formula & $C_{4} \mathrm{H}_{10} \mathrm{O}$ & $\mathrm{C}_{5} \mathrm{H}_{9} \mathrm{NO}$ \\
\hline Density $\left(\mathrm{gm} / \mathrm{cm}^{3}\right)$ & 0.81 & 1.028 \\
\hline Boiling point $\left({ }^{\circ} \mathrm{C}\right)$ & 117 & 202 \\
\hline Molar mass $(\mathrm{gm} / \mathrm{mol})$ & 74.12 & 99.13 \\
\hline
\end{tabular}

\section{Experimental procedures}

$>$ Prepare 0.25 and 0.75 solvent NMP/solvent butyl alcohol (\%wt.) in a two small vessels.

$>\operatorname{Mix}(20,60) \mathrm{gm}$. Of prepared solvent with $10 \mathrm{gm}$. Of used lubricating oil to prepare a solvent to oil ratio (2-6) \%wt. respectively.

$>$ Expose the mixture to the conditions mentioned in Table 2, according to run order

$>$ Put the mixture to a separating funnel to separate for one hour

$>$ There will be two phases extract phase (base oil + solvent) and raffinate phase (sludge)

$>$ The sludge is placed in a previously known beaker and was oven dried at $205{ }^{\circ} \mathrm{C}$ for $30 \mathrm{~min}$ where a constant weight of sample is maintained then let cooled to room temperature to obtain the weight of sludge

$>$ The percent sludge removal will be calculated

\section{RESULTS AND DISCUSSION}

Statistical analysis of the model was performed to evaluate the analysis of variance (ANOVA). Based on the preliminary experimental results, the levels chosen for the independent variables, solvent tosolvent ratio (\%wt.) (x1), solvent to oil ratio (\%wt.) (x2), Temperature (x3), mixing time (x4) and mixing speed (x5) were shown in Table 1

Table1: Experimental range and levels of the independent variables

\begin{tabular}{|c|c|c|c|c|c|c|c|c|c|}
\hline \multicolumn{2}{|c|}{$\begin{array}{l}\text { Extraction } \\
\text { temperature }\end{array}$} & \multicolumn{2}{|c|}{ Mixing time } & \multicolumn{2}{|c|}{ Mixing speed } & \multicolumn{2}{|c|}{$\begin{array}{l}\text { Solvent to } \\
\text { solvent ratio }\end{array}$} & \multicolumn{2}{|c|}{$\begin{array}{l}\text { Solvent to oil } \\
\text { ratio }\end{array}$} \\
\hline $\begin{array}{l}\text { Real } \\
\text { value }\end{array}$ & $\begin{array}{l}\text { Coded } \\
\text { value }\end{array}$ & $\begin{array}{l}\text { Real } \\
\text { value }\end{array}$ & $\begin{array}{l}\text { Coded } \\
\text { value }\end{array}$ & $\begin{array}{l}\text { Real } \\
\text { value }\end{array}$ & $\begin{array}{l}\text { Coded } \\
\text { value }\end{array}$ & $\begin{array}{l}\text { Real } \\
\text { value }\end{array}$ & $\begin{array}{l}\text { Coded } \\
\text { value }\end{array}$ & $\begin{array}{l}\text { Real } \\
\text { value }\end{array}$ & $\begin{array}{l}\text { Coded } \\
\text { value }\end{array}$ \\
\hline$X_{3}$ & $x_{3}$ & $X_{4}$ & $x_{4}$ & $X_{5}$ & $x_{5}$ & $X_{1}$ & $x_{1}$ & $X_{2}$ & $x_{2}$ \\
\hline 25 & -1 & 10 & -1 & 2 & -1 & 0.25 & -1 & 2 & -1 \\
\hline 60 & 1 & 50 & 1 & 600 & 1 & 0.75 & 1 & 6 & 1 \\
\hline
\end{tabular}


The values of independent variables were coded as the variables, $x$, in the range of +1 and -1 levels. Thus 24 run was needed in total. The mean value of the response (percent sludge removal) was obtained at different conditions mentioned and summarized in Table 2

Table2: parameter levels in coded units and the experimental and predicted percent sludge removal

\begin{tabular}{|c|c|c|c|c|c|c|c|c|}
\hline \multirow{2}{*}{$\begin{array}{l}\text { Run } \\
\text { order }\end{array}$} & \multirow[t]{2}{*}{ Block } & \multirow[t]{2}{*}{$x_{1}$} & \multirow[t]{2}{*}{$x_{2}$} & \multirow[t]{2}{*}{$x_{3}$} & \multirow[t]{2}{*}{$x_{4}$} & \multirow[t]{2}{*}{$x_{5}$} & \multicolumn{2}{|c|}{ Percent sludge removal } \\
\hline & & & & & & & Experimental & predicted \\
\hline 1 & 1 & -1 & -1 & -1 & -1 & 1 & 22.19 & 22.0163 \\
\hline 2 & 1 & -1 & -1 & 1 & -1 & -1 & 35.74 & 36.1830 \\
\hline 3 & 1 & 1 & 1 & -1 & -1 & -1 & 45.73 & 45.2496 \\
\hline 4 & 1 & -1 & -1 & -1 & 1 & 1 & 19.51 & 23.1963 \\
\hline 5 & 1 & -1 & -1 & 1 & -1 & -1 & 33.82 & 36.1830 \\
\hline 6 & 1 & -1 & -1 & 1 & 1 & -1 & 34.26 & 36.5963 \\
\hline 7 & 1 & 1 & 1 & -1 & 1 & -1 & 46.82 & 48.3430 \\
\hline 8 & 1 & 1 & 1 & 1 & -1 & 1 & 51.08 & 53.0896 \\
\hline 9 & 1 & 1 & 1 & 1 & -1 & 1 & 50.24 & 53.0896 \\
\hline 10 & 1 & -1 & -1 & -1 & 1 & 1 & 22.97 & 23.1963 \\
\hline 11 & 1 & 1 & 1 & -1 & -1 & -1 & 42.63 & 45.2496 \\
\hline 12 & 1 & 1 & 1 & -1 & -1 & -1 & 43.77 & 45.2496 \\
\hline 13 & 1 & 1 & 1 & -1 & 1 & -1 & 46.21 & 48.3430 \\
\hline 14 & 1 & -1 & -1 & -1 & -1 & 1 & 18.86 & 22.0163 \\
\hline 15 & 1 & -1 & -1 & 1 & 1 & -1 & 36.65 & 36.5963 \\
\hline 16 & 1 & 1 & 1 & 1 & 1 & 1 & 53.02 & 55.8863 \\
\hline 17 & 1 & -1 & -1 & 1 & -1 & -1 & 32.17 & 36.1830 \\
\hline 18 & 1 & 1 & 1 & 1 & 1 & 1 & 52.24 & 55.8863 \\
\hline 19 & 1 & 1 & 1 & -1 & 1 & -1 & 46.26 & 48.3430 \\
\hline 20 & 1 & -1 & -1 & -1 & 1 & 1 & 20.39 & 23.1963 \\
\hline 21 & 1 & -1 & -1 & -1 & -1 & 1 & 21.53 & 22.0163 \\
\hline 22 & 1 & 1 & 1 & 1 & -1 & 1 & 50.50 & 53.0896 \\
\hline 23 & 1 & -1 & -1 & 1 & 1 & -1 & 37.18 & 36.5963 \\
\hline 24 & 1 & 1 & 1 & 1 & 1 & 1 & 55.37 & 55.8863 \\
\hline
\end{tabular}


Table 3: results of the regression analysis

\begin{tabular}{|c|l|l|l|l|}
\hline Term & Coef & SE coef & T-value & P-value \\
\hline constant & 38.297 & 0.301 & 127.34 & 0.000 \\
\hline$x_{1}$ & 10.358 & 0.301 & 34.44 & 0.000 \\
\hline$x_{2}$ & 5.225 & 0.301 & 17.37 & 0.000 \\
\hline$x_{3}$ & 0.942 & 0.301 & 3.13 & 0.006 \\
\hline$x_{4}$ & -1.806 & 0.301 & -6.00 & 0.000 \\
\hline$x_{5}$ & 0.388 & 0.301 & 1.29 & 0.215 \\
\hline$x_{2} * x_{3}$ & 0.322 & 0.301 & 1.07 & 0.301 \\
\hline$x_{2} * x_{5}$ & -0.184 & 0.301 & -0.61 & 0.549 \\
\hline
\end{tabular}

In Table 3, it shows that the significant effect of each factor affecting the process in which it is specified by $\mathrm{T}$-values and $\mathrm{P}$-values. The larger the magnitude of $\mathrm{T}$-value and the smaller the $\mathrm{P}$-value give us indication about the considerable significance of the corresponding coefficient.

From the ANOVA analysis, it shows that according to given confidence level $(\mathrm{P}<0.05)$ the solvent-tosolvent ratio has the highest significant effect followed by solvent to oil ratio, mixing time and extraction temperature. Whereas, the interaction between solvent to oil ratio and extraction temperature and the interaction between solvent to oil ratio and mixing speed has no significant effect.

The regression analysis give this simple model

Regression equation in coded unit:-

$\%$ sludge removal $=7.60+41.43 X_{1}+2.406 X_{2}+0.0171 X_{3}-0.0903 X_{4}+0.00378 X_{5}+0.00919$

$\left(X_{2} \times X_{3}\right)-0.000460\left(X_{2} \times X_{5}\right)$

Moreover, after eliminating the non-significant factors the regression model is

$\%$ sludge removal $=6.77+41.43 X_{1}+2.612 X_{2}+0.0539 X_{3}-0.0903 X_{4}$

To obtain a general mathematical model to describe the process in un-coded unit

$\%$ sludge removal $=6.77+41.43$ solvent to solvent ratio +2.612 solvent to oil ratio +

0.0539 temperature -0.0903 mixing time

The fit of the regression model was checked by the coefficient of determination $R^{2}$. In which the value of $R^{2}$ was $98.97 \%$ which indicate that the model is accepted. Furth more, there was no evidence for lack of fit or standard deviation as shown in Table 4.

Table 4: Model summary

\begin{tabular}{|l|l|}
\hline $\mathrm{S}$ & 1.473 \\
\hline$R^{2}$ (adj) & $98.52 \%$ \\
\hline$R^{2}$ (pred.) & $97.68 \%$ \\
\hline
\end{tabular}




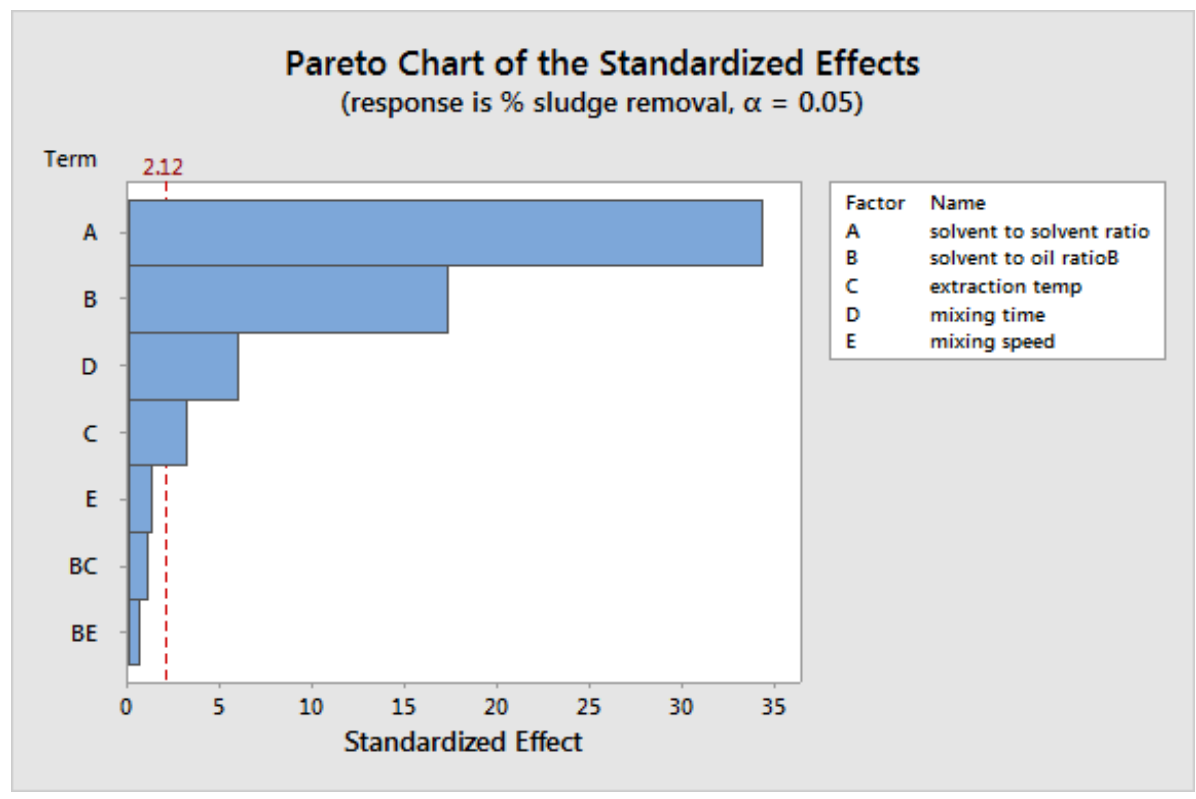

Figure 1: pareto chart

This pareto chart shown in Fig.1 give the approve the significantly effect of (solvent to solvent ratio, solvent to oil ratio, mixing time and extraction temperature) where the effect is more significantly with respect to the previous order and decreases to the lowest significant factor which is the extraction temperature. Where the effect of (mixing speed, the interaction between solvent to oil ratio and extraction temperature and the interaction between solvent to oil ratio and mixing speed) have no significant effect and can be negligible . Furth more, this chart illustrates the strength and the effect of each factor according to the following order:-
A. Solvent to solvent ratio
B. Solvent to oil ratio
C. Mixing time
D. Extraction temperature

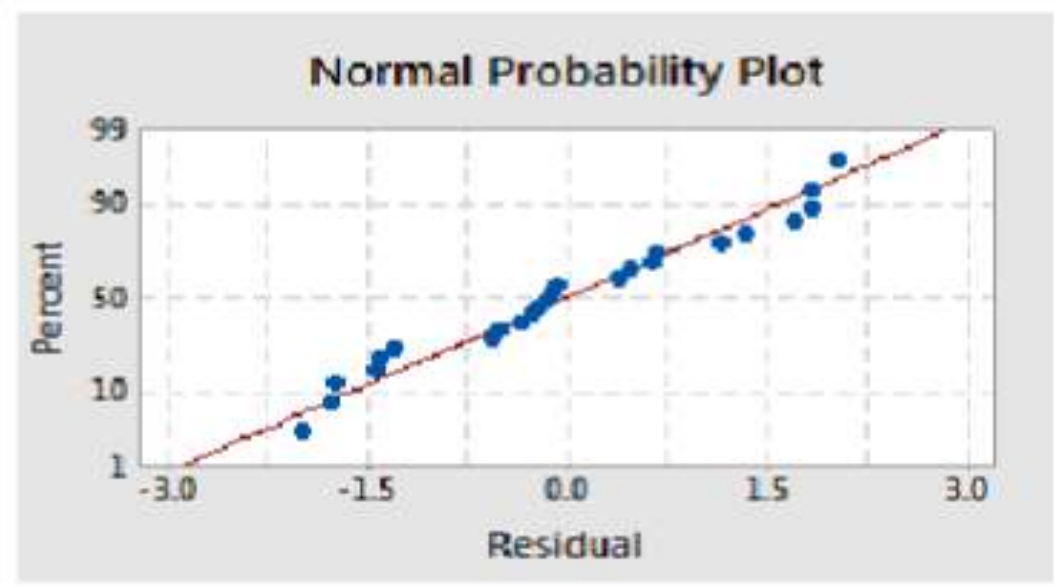

Figure 2: normal probability plot

This normal probability plot shown in Fig.2 shows a straight line in the plot of the residuals which in turns to represent a normal distribution and thus supports the adequacy of the least square fit according to the regression model. 


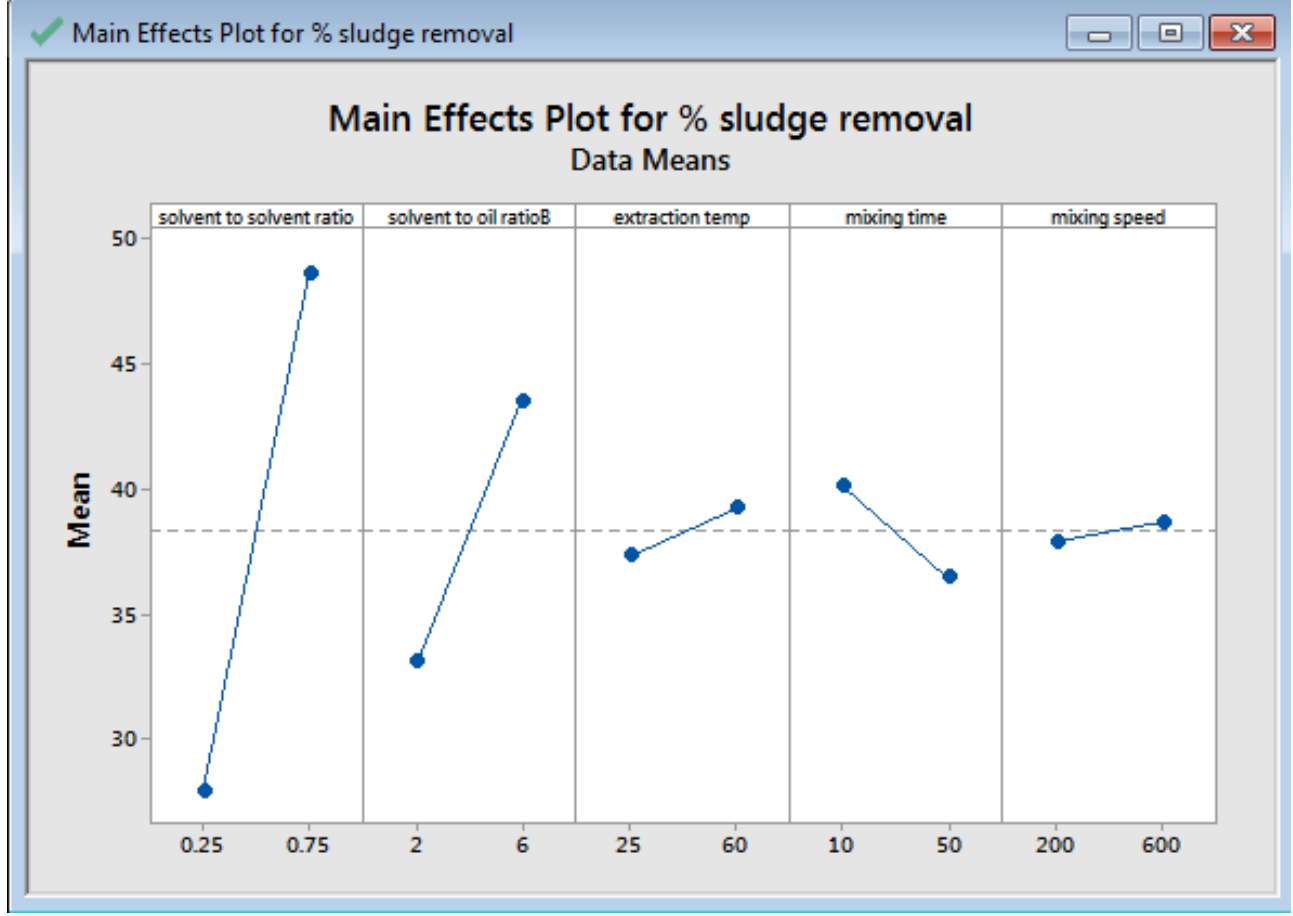

Figure 3: Main effect plot

The main effect plot shown in Fig.3 give us indication about how each factor affect the response (percent sludge removal) where it shows the highest significant factor is the solvent-to-solvent ratio and the lowest significant factor is the mixing speed. Whereas, the slope of the solvent-to-solvent ratio line is the steepest which shows greatest magnitude of the effect upon the percent sludge removal.

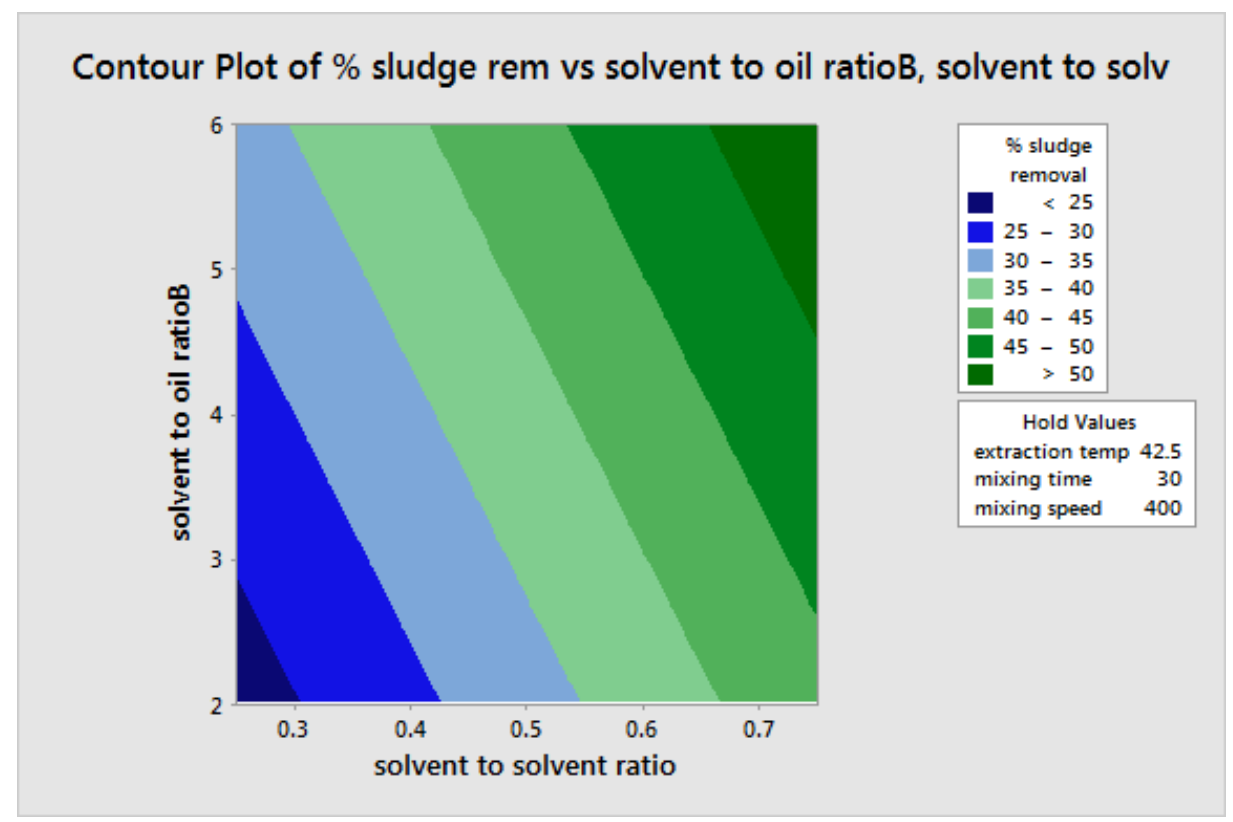

Figure 4: contour plot

This contour plot shown in Fig.4 of the percentage of the sludge removal with a colored area versus the solvent to oil ratio and solvent -to- solvent ratio where the graphs shows the highest yield or the 
highest percentage of sludge removal can be obtained at solvent to solvent ratio approximately 0.65 and solvent to oil ratio about 4.5 .

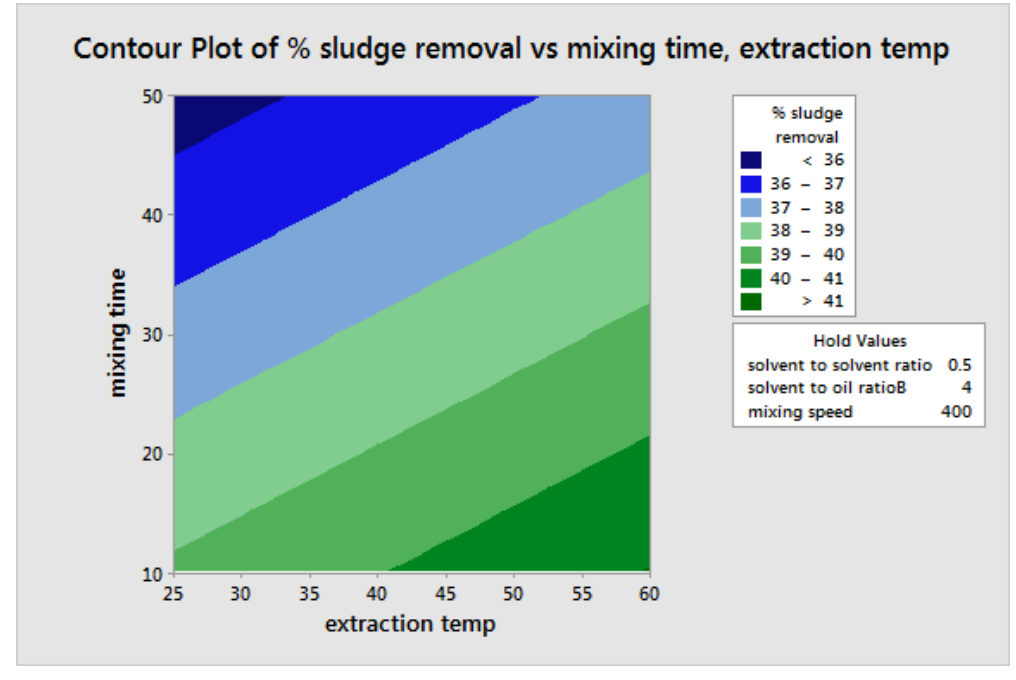

Figure 5: contour plot

This contour plot shown in Fig. 5 of the percentage of the sludge removal with a colored area versus the mixing time and extraction temperature where the graphs shows the highest yield or the highest percentage of sludge removal can be obtained at extraction temperatures varies from nearly $33{ }^{\circ} \mathrm{C}$ and mixing time about 45 minutes.

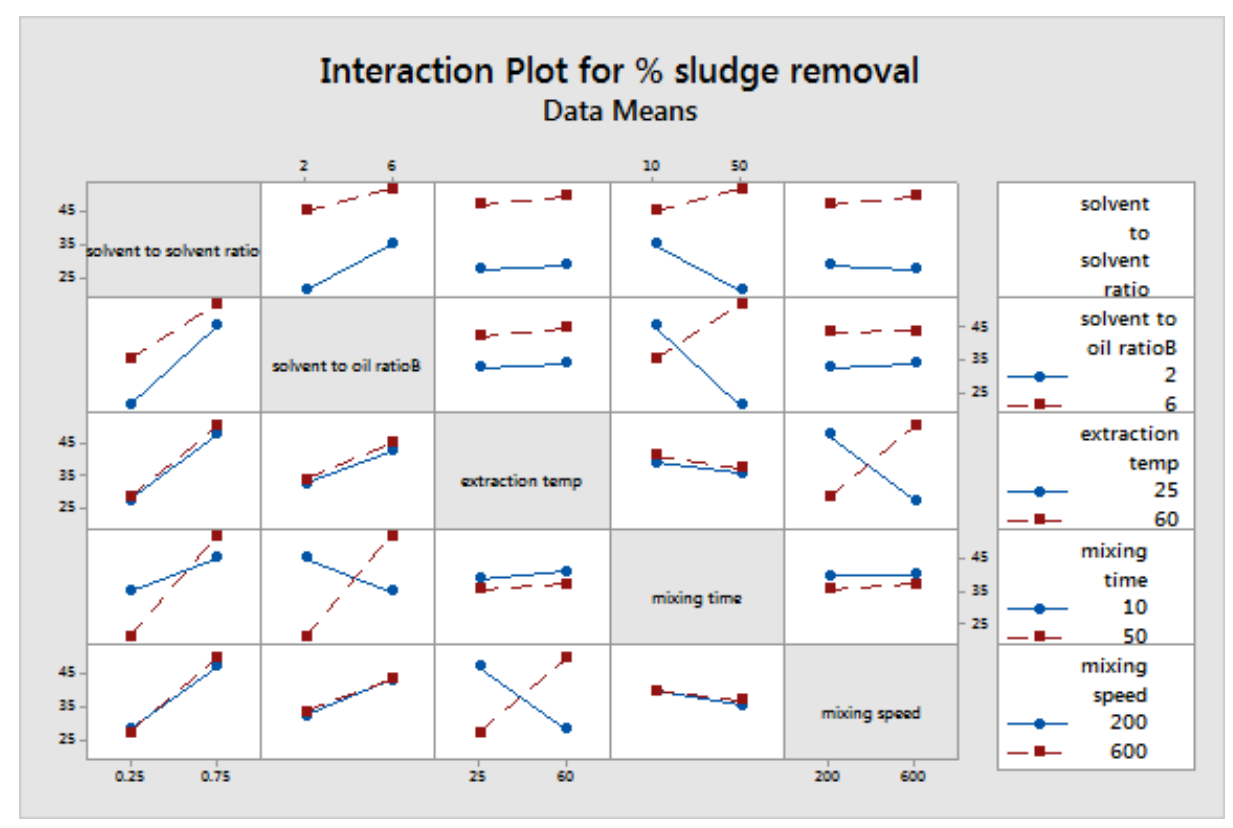

Figure 6: interactions plot

This interaction plot shown in Fig. 6 shows an indication about the behavior of each factor with the percent sludge removal which emphasis the previous plots with respect to the percent sludge removal. Where for the factor solvent to solvent ratio

The graph shows that the relation between solvent-to-solvent ratio and solvent to oil ratio give us indication about the highest percent of sludge removal for solvent to oil ratio six more than that of two 
at the same solvent-to-solvent ratio. In addition, the graph of solvent-to-solvent ratio and extraction temperature show that highest percent sludge removal exist when the extraction temperature is $60{ }^{\circ} \mathrm{C}$ more than that of $25^{\circ} \mathrm{C}$ at the same solvent-to-solvent ratio. Furth more, The graph between solvent- to -solvent ratio and mixing time shows that there is an interaction between them but the interaction is not significant as shows the data mean at solvent to solvent ratio 0.25 eliminates the mean at 0.75 (reversal) while the graph between solvent to solvent ratio and mixing speed show that the interaction occur between the two factors eliminate each other at solvent to solvent ratio 0.25 and 0.75 lines

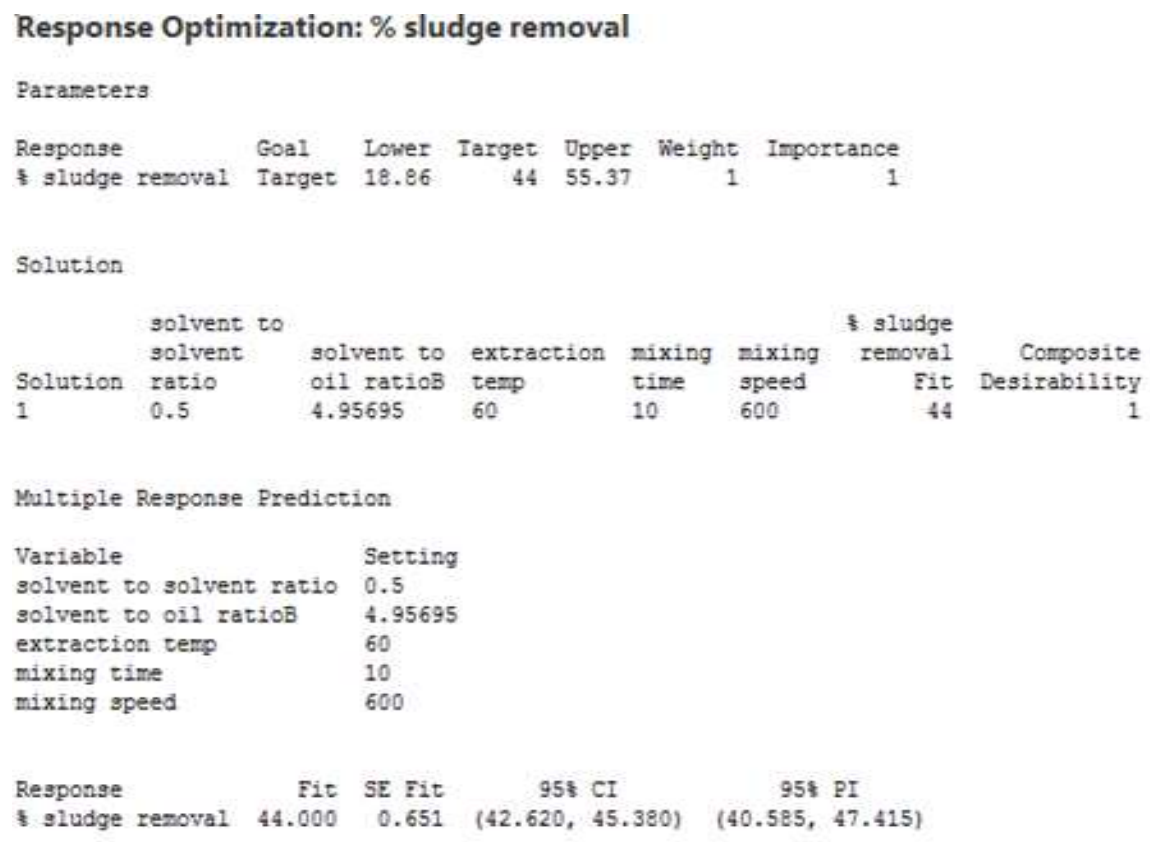

Figure 7: optimization

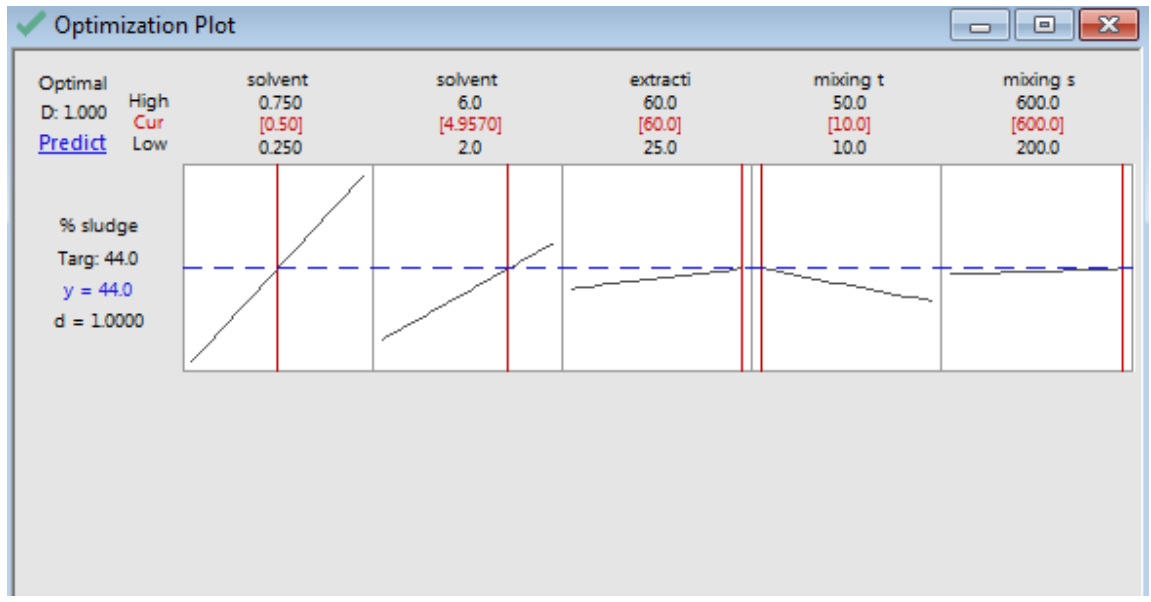

Figure 8: optimization plot

This plot shown in Fig.7 and Fig. 8 which give the optimum factors to achieve a percent sludge removal $44 \%$ where the solvent to solvent ratio is 0.5 and solvent to oil ratio is about 4.5 and extraction temperature 60 and mixing time $10 \mathrm{~min}$ and mixing speed $600 \mathrm{rpm}$

Furth more, a check experiment was done to compare the deviation on the previous result where according to the following factors given ( solvent to solvent ratio, solvent to oil ratio, extraction 
temperature , mixing time and mixing speed) the percent sludge removal obtained was 42.87 which shows a nearly value from the estimated optimization plot.

Table 5: shows the analysis of used lubricating oil and re-refining oil

\begin{tabular}{|l|l|l|l|}
\hline Test & Method & before & after \\
\hline Flash Point ${ }^{\circ} \mathrm{C}$ & ASTM-D92 & 112 & 180 \\
\hline Kinematic viscosity @ 40 & ASTM-D445 & 133.67 & 90.75 \\
\hline Kinematic viscosity @100 & ASTM-D445 & 14.32 & 10.50 \\
\hline Viscosity index & ASTM-D2270 & 106 & 108 \\
\hline Colour & ASTM color-D1500 & ------ & +3 \\
\hline Pour point & ASTM-D97 & -3 & -3 \\
\hline
\end{tabular}

Table 5, shows that there is an improvement in the physical properties of the re-refined used lubricating oil.

\section{CONCLUSION}

The effects of five experimental parameters on the percent sludge removal were investigated statistically. Fractional factorial design was used to design an experimental program to study the factors affecting the percent sludge removal in used lube oils re-refining. Mathematical model equations were obtained for the percent of extraction yield by using the experimental data and the mathematical software package MINITAB (version 17). The adequacy of the predictive model was confirmed effectively by the validation data. Predicted values were found to be in good agreement with the experimental values. $\left(\mathrm{R}^{2}=98.52 \%\right)$ is close to one hundred percent, indicating a high degree of correlation between the response and the independents variables in two responses (experimental and predicted values).

Furth more, the significantly of the factors affecting the process and their interactions have been investigated. Where the significant effects shown were the solvent- to -solvent ratio (\%wt.), solvent to oil ratio (\%wt.), mixing time and extraction temperature respectively. On the other hand, the nonsignificant factors were the mixing speed and the interaction between solvent to oil ratio and extraction temperature and the interaction between solvent to oil ratio and mixing speed.

Furth more, the optimum conditions to obtain percent sludge removal $44 \%$ was as follows (solvent-tosolvent ratio is 0.5 , solvent to oil ratio is 4.9 , extraction temperature is $60^{\circ} \mathrm{C}$, mixing time is $10 \mathrm{~min}$. and mixing speed is $600 \mathrm{RPM}$ ). The flash point of the re-refined lubricating oil was improved from 112 to $180{ }^{\circ} \mathrm{C}$ and the viscosity index improved from 106 to 108 also the most significant improving was the color, where the color of the oil changed from not clear to +3 according to the ASTM colorD1500.Finally, the blend of N-Methyl-2-pyrolidone with butyl alcohol can be used to recycle the used lubricating oil. However, the analysis could change by changing the type of the used lubricating oil be re-refined.

\section{REFERENCES}

1. I.G. Rafie R.Mohammed, waste lubricating oil treatment by extraction and adsorption. Chemical Engineering Journal.2013, 52, (36), 12689-12702 
2. A.S.Gabrah, solvent extraction parameters in re-refining of used lube oils by box-behnken experimental design. American Journal Of Enviromental Engineering and Science.2015, 2, 6, 108-113

3. M.H.Ahmed Samir Gabrah, used lubricating oil re-refining by solvent extraction. LAP LAMBERT Academic publishing,Germany.2015.

4. H.A.Elsayed, E. A.-S.-R. , Re-refining of waste lube oil via solvent Extraction followed by catalytic hydrotreatment. Egypt.J.Chem,2015,58, 6.610.

5. H.A.Durrani, M.I. Panhwar \& R.A.Kazi, Determining an efficient solvent extraction parameters for re-refining of waste lubricating oils. Mehran University research journal of engineering and technology,volume ,2012, 31, 2.105-119

6. J. lukic, A. Orlovic, M. Spiteller, J. Jovanovic \& D. Skala, Re-refining of waste mineral insulating oil by Extraction with N-Methyl-2-Pyrrolidone. Elsevier. Retrieved from Elsevier: www.elsevier.com,2005

7. A.S.Gabrah, Study on used lubricating oils re-refining by solvent extraction. 2009.

8. M. Roci, Minimizing Variation in width and height of cutting tool inserts. 2016.

9. J.L.Jaynes, Contributions in design of experiments : Methods and Applications. 2013

10. Alexandria Petroluem Company(APC), One of the egyptian general authority's(EGPA) companies,Max,Alexandria,Egypt

11. X.Ding, W. Wong, \& H. Quan Xu, Application of fractional designs to study drug combinations. Retrieved from www.research gate.net,2018

\section{Corresponding author: M.Attia,}

Department of chemical engineering, Alexandria University, Alexandria, Egypt 